\title{
A percepção do corpo e o autocuidado em sujeitos com diabetes mellitus 2 : uma abordagem fenomenológica
}

\section{| ${ }^{1}$ José Roque Junges, ${ }^{2}$ William Vieira de Camargo |}

Resumo: Este trabalho apresenta uma pesquisa de natureza qualitativa, que teve como objetivo analisar a percepção do corpo e o autocuidado em sujeitos acometidos por diabetes mellitus 2. Foram entrevistados dez participantes, atendidos por uma Estratégia de Saúde da Família localizada na região metropolitana de Porto Alegre-RS. Como recurso metodológico, utilizou-se a entrevista semiestruturada; os dados foram analisados através da análise de conteúdo do tipo temática, proposta por Bardin. Como matriz teórica, utilizou-se a perspectiva fenomenológica de Merleau-Ponty. A análise das narrativas possibilitou a criação de duas categorias: 1) corpo alterado: enfrentando o inesperado; 2) corpo assumido: aprendendo a conviver com a doença. A interpretação dos dados revelou que os sujeitos apresentaram atitudes de surpresa, sentimento de tristeza, não aceitação frente às alteraçóes do corpo, mas também conformação em relação ao diagnóstico. Os sujeitos passaram por dificuldades alimentares e gerenciamento de medicamentos até assumirem o corpo alterado pela incorporação de novos hábitos. Como conclusão, destaca-se que somente com o alinhamento do corpo habitual ao corpo atual, pela incorporação dos procedimentos de tratamento, é que a atitude de autocuidado começa a fazer parte do cotidiano.

> Palavras-chave: saúde pública; doença crônica; diabetes mellitus; corporeidade; autocuidado.

\author{
1 Programa de Saúde Coletiva, \\ Universidade do Vale do Rio dos \\ Sinos. São Leopoldo-RS, Brasil \\ (roquejunges@hotmail.com). \\ ORCID: 0000-0003-4675-0993 \\ 2 Programa de Saúde Coletiva, \\ Universidade do Vale do Rio \\ dos Sinos. São Leopoldo-RS, \\ Brasil (william_camargo111@ \\ hotmail.com). \\ ORCID: 0000-0002-8093-4019.
}

Recebido em: 27/12/2019 Aprovado em: 03/03/2020 Revisado em: 30/08/2020 


\section{Introdução}

O aumento das doenças crônicas exigirá grandes transformaçôes no sistema de saúde, porque este está preparado para fazer frente a eventos agudos ocasionais, quando se trata do acompanhamento das condiçóes crônicas que demandam cuidado longitudinal e permanente (MENDES, 2012). Nesse quadro, as exigências da diabetes mellitus (DM) têm um forte impacto na assistência, por sua elevada prevalência (ISER et al., 2015). Entretanto, não impacta apenas a prevalência, mas sobretudo o tipo de acompanhamento que demanda o cuidado de pessoas diabéticas, devido à necessária atenção e sensibilidade para captar os sintomas da doença que se revelam no corpo e agir em consonância com eles. Isso significa dar atenção e protagonismo à subjetividade desses pacientes, para possibilitar a compreensão desses sinais corporais e o incentivo de práticas de gerenciamento e autocuidado da doença, superando propostas clínicas verticalizadas dos profissionais, centradas em procedimentos prescritivos (LUCHERINI, 2016).

Para esse conhecimento dos sinais e incentivo ao gerenciamento, importa compreender as representaçóes sociais dos pacientes sobre a diabetes. Eles, em geral, têm consciência de sua responsabilidade para que o tratamento tenha eficácia e compreendem que mudanças de estilo de vida são necessárias. Isso leva a que, muitas vezes, tenham uma postura resignada diante da dificuldade de superar a inércia e instaurar as mudanças inevitáveis. Esse processo começa com a descoberta do diagnóstico que sempre é uma surpresa, com consequências emocionais, e demonstração do desconhecimento da doença que já demonstrava seus sintomas no corpo, revelados pelos exames. A confirmação dos resultados conduz ao projeto de tratamento que sempre inclui medicamentos, dieta e exercícios físicos que os pacientes têm dificuldade de implementar, principalmente aqueles que demandam uma mudança na rotina da vida cotidiana. Os aspectos nutricionais da dieta são o desafio maior pelos aspectos culturais implicados na sua implementação devido às consequências sobre os relacionamentos em encontros familiares e sociais (COSTA; COUTINHO, 2016).

Para fazer frente aos sintomas da diabetes, os pacientes recorrem inicialmente ao subsistema profissional onde foi feito o diagnóstico e dadas as primeiras instruçóes terapêuticas, mas depois apelam a conhecimentos e recursos oferecidos pelo seu subsistema familiar, baseados em experiência e tradição de quem já lidou com a 
doença e, por fim, valem-se também de meios alternativos, proporcionados pelo subsistema popular, como benzedeiras e imposição de mãos (SILVA et al., 2006).

A não adesão ao tratamento geralmente está associada ao conhecimento limitado sobre a cronicidade da doença e o controle de seus sintomas no corpo. Essas pessoas consideram que podem controlar a doença com os medicamentos e a escolha de um tipo de alimento durante as refeiçóes, como uma vez foi recomendado pelos profissionais. A tentativa de adaptar essas recomendaçóes ao estilo de vida sem uma mudança de hábitos pode acarretar sérios problemas (PUCCI et al., 2018). Esse tipo de situação exige uma reflexão e uma atenção movidos pela perspectiva da integralidade que dê conta da experiência do adoecimento (CANESQUI, 2018) e dos aspectos psicossociais do silenciamento da doença (LUCHERINI, 2019), para que seja possível um acompanhamento longitudinal próximo da pessoa em relação a esses aspectos que afetam a vida como um todo da pessoa com seus reflexos sobre o corpo que ela precisa aprender a auscultar e a lidar.

Essas diferentes considerações terminam por incidir sobre o corpo do diabético, que é o sismógrafo da revelação e da tomada de decisóes sobre sua doença. As tensôes entre as experiências do corpo saudável, as revelaçóes do corpo alterado e a integração dessas alteraçóes no corpo dependente do sujeito são o grande desafio para o cuidado de pessoas com diabetes (SILVA et al., 2010).

A pesquisa assumiu a perspectiva fenomenológica de Merleau-Ponty (2015) como matriz teórica para analisar a percepçáo sobre o corpo em pessoas com diabetes. $\mathrm{O}$ autor conceitua "corpo" como uma realidade que não pode ser reduzida ao aspecto biológico, mas entendido como corpo sujeito, base da existência e da experiência no mundo, capaz de mediar a possibilidade de significaçáo das vivências. Merleau-Ponty expressou essa visão no conceito de corpo próprio, entendido como a subsunção da realidade corpórea pela subjetividade, pela qual o ser humano se situa no mundo (MERLEAU-PONTY, 1999).

Merleau-Ponty (1999) distingue duas camadas existenciais no corpo próprio: o corpo habitual e o corpo atual. Na primeira, situam-se as vivências do passado, os gestos, os hábitos, que já não correspondem às manifestaçôes da segunda. Esta, por sua vez configura uma nova condição corpórea. Por vezes, o corpo habitual se recusa a adaptar-se a uma nova condição corporal. Como forma de continuidade do viver, o corpo habitual pode não suportar a nova condição, ignorando sua limitação atual, com a recusa da deficiência como um avesso da inerência ao mundo. 
A transposição de um corpo sadio para um corpo, agora privado, passa a ser não uma limitação real, mas algo passageiro, não reconhecido de fato como alteração no corpo. Pela aplicação de técnicas ao corpo, os pacientes incorporam procedimentos e instrumentais terapêuticos propostos pelos profissionais para fazer frente e gerenciar as consequências negativas, experimentadas no corpo atual, possibilitando uma integração entre o corpo habitual e o atual. Como exemplo de técnica auxiliar ao corpo atual para reencontrar sua habitualidade, o autor aponta o uso da bengala integrada ao corpo, não mais considerada como um apêndice corporal (MERLEAU-PONTY, 1999). Os conceitos de corpo habitual e corpo atual servirão de categorias para analisar a percepção do corpo em diabéticos. Em artigo anterior, Ataíde, Damasceno e Moreira (2001) usaram essa mesma matriz teórica para pesquisar adolescentes com diabetes que se percebiam como corpo dicotomizado pelo acento dos profissionais nas prescrições e a falta de atenção aos aspectos existenciais da doença.

Partindo da ideia de que os sujeitos acometidos por DM passam por transformaçóes após o diagnóstico com repercussōes sobre seu corpo, o objetivo do artigo é compreender a percepção da pessoa acometida por diabetes sobre seu corpo e suas repercussóes sobre as práticas de gerenciamento e autocuidado da doença.

\section{Metodologia}

Para alcançar o objetivo proposto, utilizou-se uma abordagem de natureza qualitativa, visando obter dados do contexto e da história de vida dos participantes através de entrevista em profundidade. Utilizou-se o referencial filosófico da fenomenologia, que é uma das formas de compreender o ser humano através da facticidade da experiência de sua vida e da sua exposição tal como ela se manifesta. Para tal fim, utilizou-se a obra Fenomenologia da percep̧cão, de Merleau-Ponty (1999).

A pesquisa foi realizada na Estratégia Saúde da Família (ESF) de um município da regiáo metropolitana de Porto Alegre-RS, de onde foram selecionados os participantes de ambos os sexos, que apresentavam estado cognitivo preservado, com no mínimo de dez anos de diagnóstico clínico de diabetes mellitus tipo 2. Escolheuse tal duração, porque nesse período de tempo os sujeitos já passaram por diversas situaçôes, como: descompensaçâo, internaçôes, dificuldades alimentares, entre outros. Foram selecionados dez (10) participantes, dos quais oito eram mulheres. Para essa seleção, a Secretaria de Saúde do município indicou a equipe com maior 
número de portadores de diabetes. A equipe indicou de início dez participantes, tendo presente o critério de dez anos de diagnóstico e maior uso dos serviços de saúde. A média de idade dos participantes foi de 67,4 anos ( $\pm 57-86)$, com média de diagnóstico clínico de DM de 19,5 anos ( $\pm 10-36)$, sendo a maioria caucasianos e aposentados. Quanto à escolaridade, predominou o ensino fundamental incompleto.

Como instrumento de coleta de dados, utilizou-se a entrevista em profundidade do tipo semiestruturada (MORÉ, 2015). As questôes norteadoras abertas foram: 1) fale do que você sentiu quando soube do diagnóstico de diabetes; 2) de como lidou com as consequências desse diagnóstico, o que mudou na sua vida; e 3) quais foram os efeitos que experimentou no seu corpo à medida que os anos foram passando. A coleta dos dados foi realizada no domicílio de cada um dos participantes. Para essas visitas, o pesquisador sempre foi acompanhado por uma agente comunitária de saúde, servindo de contato e facilitadora. As entrevistas tiveram a duração de uma hora, sendo gravadas e posteriormente transcritas. Quando se foi chegando ao número de entrevistados, indicado pela equipe, notou-se que foi atingido o ponto de saturação dos dados, não sendo necessário incluir novos participantes (NASCIMENTO, 2018). A análise dos dados foi realizada através da análise de conteúdo do tipo temática proposta por Bardin (2011). O projeto foi desenvolvido no ano de 2016.

O projeto de pesquisa foi submetido à Plataforma Brasil e aprovado pelo Comitê de Ética em Pesquisa da UNISINOS com protocolo número 1.961.510. Para preservar o anonimato, os participantes receberam nomes fictícios.

\section{Resultado e Discussão}

A análise do material empírico coletado possibilitou a criação de duas categorias temáticas, a saber: corpo alterado: enfrentando o inesperado e corpo assumido: aprendendo com a doença.

Os sujeitos acometidos pela diabetes, em geral, se referem ao seu corpo como saudável, não levando em consideração as especificidades que o caracterizam no momento atual, revelados pelo diagnóstico. $\mathrm{O}$ corpo habitual tem dificuldade de reconhecer a limitação corpórea, continuando a viver os mesmos hábitos que praticava antes da manifestação dos sintomas da doença. Para que essa nova condição corpórea seja mais bem gerenciada, os sujeitos procuram incorporar, no seu cotidiano, as orientaçóes dos profissionais para reencontrar o equilíbrio do corpo habitual, agora 
dependente das tecnologias clínicas. Esse processo aparece na passagem do corpo alterado pela limitação para um corpo assumido.

\section{Corpo alterado: enfrentando o inesperado}

Nesta categoria, apresentam-se as percepçôes dos sujeitos entrevistados em relação ao momento do diagnóstico clínico por um profissional da saúde. Apesar de alguns sintomas da doença já se apresentarem em seu cotidiano, os sujeitos não o relacionavam como sendo em decorrência de DM. Sendo assim, vivenciam algo inesperado, apresentando atitudes de surpresa, bem como de não aceitação, ao mesmo tempo de conformação em relação ao diagnóstico.

Isso aparece no caso de Ana, que soube que tinha DM após apresentar sintomas de descompensação e ser encaminhada ao médico. Antes do fato citado, Ana relatou que vinha sentindo alguns desconfortos corporais, característicos da DM, que nunca causaram grandes problemas em seu cotidiano. Após um episódio de hipoglicemia severa, que apresentou tonturas, sudorese excessiva, tremores, que levaram a paciente a buscar auxílio médico, alguns exames clínicos foram solicitados e a paciente foi diagnosticada com DM. Conforme o relato de Ana, no momento que lhe foi dado o diagnóstico, ela sentiu-se surpresa e, ao mesmo tempo, esboçou uma não aceitação do diagnóstico clínico.

[...] fiquei bastante surpresa e triste, também! Porque a única coisa que eu não queria ter na minha vida era diabete! (Ana, 58 anos).

Ana tem um fator hereditário em relação ao DM em sua família. Portanto, ao trazer o sentimento de tristeza e a afirmação de que nunca queria ter DM, era por ter vivenciado algumas situações de dificuldades e principalmente de restrições que seus familiares passaram devido aos cuidados que a doença requer. O convívio desde pequena com tais situaçóes favoreceu a construção de fantasias do senso comum em relação a esta doença

[...] porque, pelo que os antigos falavam. Eles sempre diziam que o diabete era uma doen-
ça que matava aos poucos as pessoas. Que destrói os órgãos... (Ana, 58 anos).

Assim, sua percepção sobre a doença, revelada pelos exames do subsistema profissional, foi confrontada com a experiência e os conhecimentos de seu subsistema familiar que ajudaram a reconhecer e a interpretar os dados clínicos, demonstrados pelo diagnóstico (SILVA et al., 2006). 
Ana tem dificuldade em aceitar a doença e as limitaçôes que ela irá impor, fazendo-a resistir em aceitar o diagnóstico, baseada em sua experiência familiar. $\mathrm{Na}$ perspectiva de Merleau-Ponty (1999), isso pode ser compreendido como uma forma do sujeito manter-se em um corpo habitual, saudável, não necessitando reconhecer as limitações e assumir as atitudes correspondentes. A não aceitação do diagnóstico é a única possibilidade de continuar seus projetos de vida, ainda que se estabeleça uma ambiguidade entre o corpo habitual e o corpo atual.

Ainda sob a ótica de Merleau-Ponty (1999), a não aceitação plena da doença apresenta-se como possibilidade da continuidade do viver, uma vez que corpo próprio não se configura com vivências instantâneas do corpo atual, necessitando de experiências significativas para que incorpore um novo modo de viver que se tornará habitual. Assim, o apego ao corpo habitual é a possibilidade de continuar vivendo, base para construir significados e situar-se no mundo.

Estudo realizado por Lucherini (2019) com autobiografias de pessoas com diabetes demonstrou que alguns apresentam histórias heroicas de superação, enquanto que outros demonstram narrativas caóticas de não aceitação. Independentemente dessa classificação, todas autobiografias apontaram que problemas e preocupaçôes ligados a diabetes podem ser escondidos e silenciados para não experimentar os sinais do corpo alterado. Por isso é necessário ter presente que a experiência da diabetes expressa sentimentos, emoçóes e afetos difíceis de representar e nunca plenamente conhecidos.

Estudo desenvolvido por Touso et al. (2016) demonstrou que pessoas com diabetes têm dificuldades emocionais e psicológicas no enfrentamento da doença com respeito a sua aceitação e repercussóes sobre a vida cotidiana e quanto ao modo de perceber a patologia em relação às suas limitações e aos sentimentos de incapacidade e inabilidade que ela acarreta.

Assim como Ana, Sonia, ao receber o diagnóstico de DM, relatou sentimento de tristeza, pois lhe vieram recordaçôes negativas do passado, de situaçôes que ela vivenciou com seu padrasto, quando ajudou sua mãe a cuidar dele, já que ele tinha sérias complicaçôes devido ao DM. Novamente, as vivências do subsistema familiar ajudaram a compreender as alteraçôes do corpo, trazendo sentimento de tristeza para a vida presente desses sujeitos, uma vez que eles sentem medo de passar pelas situaçóes difíceis que as pessoas próximas vivenciaram, como vemos no relato a seguir:

Naquele momento, me senti a pessoa mais triste do mundo. [...] porque eu sabia o meu padrasto tinha diabetes! Eu disse: "será que eu vou enfrentar tudo aquilo que o seu João fazia para nós?” (Sonia, 72 anos). 
Observa-se que a percepção de Ana e de Sonia sobre as limitações do corpo alterado é reflexo de conhecimentos do seu subsistema familiar, decorrentes de experiências e complicaçóes vivenciadas com parentes próximos. Essas repercussóes do subsistema familiar, na experiência da doença, dependem de processos interativos contextuais, criadores de quadros de referência internalizados pelos sujeitos. Por isso é necessário saber conjugar as emoçôes e os sentimentos produzidos pela enfermidade com suas representaçóes sociais que apontam para as condiçóes históricas da experiência do adoecimento. O corpo é uma referência essencial dessa experiência (CANESQUI, 2018).

Para Luís, o diagnóstico de DM foi recebido com certa naturalidade, por se tratar de uma experiência nova, sem que houvesse referenciais da experiência de pessoas familiares próximas que haviam lidado com a doença. Luís procurou auxílio médico após apresentar complicações ligadas com a visão, um sintoma típico da DM. Além de não ter essas experiências, Luís não tinha nenhum conhecimento, nem mesmo empírico, em relação à doença, conforme se observa na narrativa abaixo:

O que que eu ia dizer [...] só perguntei o que era. Na verdade, a gente só ouvia falar [...]. Mas fazer o que... não dá para fugir. Já que aconteceu, tem que encarar! (Luís, 57 anos).

Mesmo sem saber o que era essa doença, Luiz, ao contrário de uma não aceitação, procurou adaptar-se frente ao diagnóstico. Como se pode observar em seu relato, ele expressa uma atitude de enfrentamento em relação à doença, com as expressôes: "não dá para fugir" e "tem que encarar". Por sua vez, Silvio conta que recebeu o diagnóstico com naturalidade, relatando que sempre teve uma alimentação desregrada, porque não comia saladas, frituras em excesso, tomava refrigerante, realizava poucas refeições por dia. Assim, Silvio compreendia que havia algo errado com o seu corpo habitual, mas mesmo assim manteve-se calmo.

Eu encarei, vamos dizer assim, com naturalidade, porque alguma coisa de errado tinha que ser cessado... Qual era? corrigir... tirar os excessos (Silvio, 68 anos).

Ainda que Silvio não conhecesse o processo fisiopatológico da doença, compreendeu que os excessos cometidos no passado, quanto à alimentaçáo, causaram prejuízos, manifestados no seu corpo atual. Toma consciência que é necessário assumir as alteraçóes no seu corpo, mudar seus hábitos para encontrar o reequilíbrio do seu corpo habitual. Nota-se, tanto em Luís quanto em Silvio, aquilo que os autores chamam de "postura resignada" (COSTA; COUTINHO, 2016), que 
expressa, ao mesmo tempo, a vontade mudar, mas também a dificuldade de superar a inércia e instaurar novos hábitos.

A pessoa com diabetes somente tomará consciência de sua condição, quando sofrer restrição alimentar, devido às alteraçôes do seu corpo e consequentes limitaçôes que experimentará no mundo que o cerca. Essas restriçôes fazem surgir diferentes tipos de discursos sobre normas dietéticas a serem seguidas, dependendo das representaçôes sociais em relação à alimentação (AMORIM; RAMOS; GAZZINELLI 2018).

A percepção sobre o corpo nos acometidos pela DM acontece pela separação, no mundo vivido, entre os dois níveis do corpo. A surpresa diante do diagnóstico reflete-se nas consequências sobre a integridade do corpo habitual, pois as alteraçóes e as limitaçôes corporais, apontam para a necessidade de adaptar-se às necessidades do corpo atual acometido pela doença. Essa sensação relaciona-se com a totalidade corpórea, expressa na consciência plena e completa em relação ao corpo e na dificuldade em aceitar a doença, como fazendo parte dessa unidade corpórea. Mas apresenta-se também como possibilidade de adaptações, frente às alterações e limitaçôes do corpo atual, assumindo novos hábitos e esquemas corporais, facilitados pela assunção de técnicas terapêuticas de cuidado, que conformam um novo corpo, assumido como habitual, mesmo que dependente desses meios (MERLEAU-PONTY, 1999).

Essa conformação do corpo está também ancorada no entorno social, porque o corpo não é apenas a subjetividade corporificada, mas é o meio de inserção no seu mundo. A doença atinge essas duas dimensôes do corpo. Quando o corpo adoece, a experiência subjetiva da doença não depende apenas das sensaçôes corporais do sujeito, mas igualmente das construçóes sociais do seu entorno que configuram a percepção do corpo e da enfermidade (HIGUERAS, 2016). As limitaçóes do corpo atual alterado são reconhecidas como algo temporalmente passageiro, na busca de restabelecer o corpo habitual, base da sua experiência de vida e do seu situar-se no mundo. Assim, o tempo provisional, passageiro, experimentado pelos ritmos alterados do corpo que vulneram o sujeito está em dissonância com o tempo existencial que configura os significados para a vida. Enquanto essas duas temporalidades não forem integradas por uma narrativa de significado, o corpo permanecerá cindido (JOWSEY, 2016).

Por isso, a importância da duração da experiência da doença, isto é, do tempo de aprendizado para lidar com as alteraçóes do corpo ou, como dizem os entrevistados, o tempo necessário para aprender. A duração do tempo, experimentada nos sinais 
e ritmos do corpo alterado, é o elemento crucial do aprendizado para lidar com a doença (KNECK; KLANG; FAGERBERG, 2012). As situaçôes desencadeadoras da sobrecarga da diabete sobre a vulnerabilidade e a temporalidade se expressam no corpo, base do aprendizado de uma nova compreensão de si mesmo e do mundo, possibilitada pela experiência da duração da doença (KNECK et al., 2016). Essa dimensão temporal da doença, como base do aprendizado com as alteraçóes do corpo, é o caminho para conviver com as limitaçôes e lidar com o cuidado do corpo transformado.

\section{Corpo assumido: aprendendo a conviver com a doença}

Passado o processo inicial da surpresa do diagnóstico e a emergência da ambivalência entre o corpo habitual e o corpo atual, os entrevistados apresentaram a necessidade de reconfigurar seus hábitos diante do processo de doença. Desta maneira, na busca do resgate do corpo habitual, as pessoas passaram a usar recursos diversificados, influenciadas pelas orientaçôes das equipes de saúde, para, assim, fazer frente às alteraçôes do corpo atual, reveladas pelo diagnóstico. Esses recursos podem ser medicamentos, dieta alimentar e exercícios físicos. Entre estes, o mais desafiador é a alimentação, difícil de aceitar e de implementar.

Pode-se observar esse fenômeno na narrativa de Silvio, relatando que, a partir do diagnóstico da doença, se deu conta do seu desregramento alimentar:

Teve que acontecer comigo, para eu realmente me conscientizar dos males... dos malefícios, que toda essa cadeia alimentar, que a gente come, que é prejudicial... (Silvio, 68 anos).

Silvio assume a postura resignada que, no fundo, expressa a discrepância entre as prescrições da equipe e as açôes verdadeiramente efetivadas, revelando a inviabilidade de implementar essas recomendaçóes no cotidiano da vida, devido à alimentação insuficiente e inadequada para um trabalhador, como Silvio, ou ainda porque os alimentos clinicamente permitidos são caros. Contudo, essas explicaçôes não conseguem dar conta do real motivo da dificuldade do seguimento da dieta, que está ligado ao imaginário cultural do uso e da seleçâo de alimentos que interferem na própria socialização, pois as restriçôes alimentares protegem contra danos futuros, mas provocam uma vida de privações e proibições que podem ser malvistas pelo entorno social. Por isso, é necessário estar atento às representaçôes sociais da alimentação (AMORIM; RAMOS; GAZZINELLI, 2018). 
Embora não seguindo as recomendações dietéticas à risca, as pessoas com diabetes em geral afirmam que controlam a alimentação, sugerindo que se trata de evitar alguns tipos de alimentos em determinadas ocasióes, pautados pelos diferentes discursos sobre a dieta alimentar. Mas, por outro lado, são também motivados em suas escolhas alimentares pela construção social de um corpo saudável veiculado pela sociedade do consumo (SANTOS et al., 2019).

Essa atitude de adaptação da dieta aparece em Cláudia, porque ela foi diagnostica com DM ainda muito jovem, aos 25 anos de idade. Ela tem um histórico familiar de pessoas diabéticas. Por isso, ela conhecia o quadro clínico correspondente, bem como os cuidados necessários, mesmo assim não os assumia, expressando uma não aceitação do processo de adoecimento.

Quando a gente é mais nova, a gente não dá bola. Acha que é uma coisa normal. Conforme o tempo vai passando, vai caindo a ficha da gente. (Claudia, 61 anos).

Ainda que o processo de adoecimento exigisse de Claudia mudanças, ela náo atentava para as necessidades de seu corpo atual, na busca por reestruturar seus hábitos para atingir níveis de autocuidado. Estando presa ao corpo habitual, o qual não lhe exigia demasiada atenção, Claudia mantinha a alimentação desregrada, com dificuldades em aderir às orientaçóes dos profissionais de saúde, desconsiderando os cuidados necessários em relação ao DM. Como forma de minimizar os malefícios do exagero alimentar, fazia uso de medicação, além do prescrito, como compensação na tentativa de regularizar a hiperglicemia:

Eu pensava assim... vou tomar medicaçáo depois, e mais tarde passa. Daí eu comia doce, comia alguma coisa que tinha em alguma festa. Eu chegava em casa e tomava metformina, tomava insulina, e vai passar. Mas é bobagem... é o pior erro da gente. (Claudia, 61 anos).

Cláudia procurava preservar sua autonomia alimentar com o uso de medicamentos para combater os efeitos provocados pelo não seguimento da dieta. A questão é como conjugar a autonomia e o gerenciamento da diabetes. Para o manejo do controle glicêmico, é muito importante o fortalecimento da autonomia do paciente para a qual é essencial o suporte dos profissionais, mas igualmente a ajuda do sistema informal dos familiares e amigos (LEE et al., 2019).

Para Cláudia, foi necessário assumir novos hábitos para poder administrar a doença em seu corpo atual.

Eu tive que começar a sentir, porque a diabetes é uma doença lenta e silenciosa. [...] a gente tem e não da importância. Daí quando a gente começa a sentir... aí a gente dá importância 
[...]. Porque vai atingindo mais a gente! o problema vai se agravando mais [...] até passar mal, ir para o hospital [...]. Daí dá problema, e cada dia vai piorando... (Claudia, 61 anos).

Observa-se que após essa atitude de não aceitação em relação à doença, especialmente em decorrência de descompensaçôes, Cláudia pode reconhecer as limitaçôes do corpo atual, reconfigurando hábitos em busca de autocuidado. Para Merleau-Ponty (1999), habituar-se diz respeito à capacidade de adaptação do ser diante do mundo, modificando sua existência, pela incorporação de recursos e potencialidades dos diferentes subsistemas de saúde, profissional, familiar e popular, como formas de enfrentar as limitaçóes corporais. Assim, os sujeitos encontram maneiras próprias de adaptar seu corpo habitual às alteraçôes do corpo atual.

Um dos fatores mais enfatizados pelos entrevistados é o uso de medicamentos, caracterizados como uma tecnologia que necessita ser incorporada aos hábitos como exigência do corpo atual. Para Laura, o desafio relacionado ao gerenciamento do autocuidado estava ligado ao uso da insulina, pois a dificuldade em assimilar o uso deste medicamento aos seus hábitos estava relacionada com experiências vividas no contexto familiar. Quando Laura era pequena, morava com a avó, que fazia o uso de insulina. Por não tomar os devidos cuidados com armazenamento e higienização do material utilizado, a avó tinha feridas e hematomas na região onde aplicava o medicamento e Laura não queria que o mesmo acontecesse com seu corpo. De novo, aparecem as experiências do subsistema familiar como um fator determinante da representação da doença e sua percepção no corpo. Contudo, a convivência com a doença e o processo de tratamento orientado pelos profissionais de saúde fizeram com que ela aprendesse a forma correta de aplicação, reconhecendo os benefícios deste tratamento.

Eu aceito [...] a insulina! Achei que ela ia provocar danos [...] mas para mim, ela me fez muito bem! (Laura, 60 anos).

Percebe-se, assim, que no processo de conviver com a doença, o uso de insulina representa um aspecto central do gerenciamento do tratamento, como uma forma de autocuidado. Esse uso de meios técnicos, como a insulina, favorece o enfrentamento dos sintomas do corpo atual, sendo um fator de harmonização entre esse corpo alterado e o corpo habitual. Contudo, esse gerenciamento da insulina exige adaptaçôes quanto ao horário mais adequado para seu uso e quanto ao ajuste das doses de acordo com a observação dos sinais no corpo. Esse fato significa a não 
passividade do diabético diante da prescrição médica, adaptando a medicação aos contextos, experiências e situaçóes do cotidiano da vida, possibilitando um auto rastreamento e gerenciamento de sua condição (LUCHERINI, 2016; DANESI; PRALONG; PIDOUX, 2018). Para esse manejo, a automonitorização dos níveis de glicemia pelo uso do glicosímetro é um meio técnico eficiente para aferir os sinais corporais e calibrar a dose de insulina (SOUZA et al., 2018). Assim, as pessoas buscam reestruturar sua forma de viver, recorrendo a orientaçóes do subsistema profissional, mas adaptando-as aos ritmos existenciais, como aparece na narrativa de Claudia:

Então tem que procurar fazer as coisas da melhor forma possível para a vida. É isso que eu penso que a pessoa tem que fazer. (Claudia, 61 anos).

Através do apoio das equipes de saúde, Laura e Claudia foram aprendendo a fazer o gerenciamento do tratamento e do autocuidado, coadjuvadas pelos conhecimentos e experiências do subsistema familiar e popular do seu entorno. O estudo de Lopes (2015) explicita as implicações da posição ocupada pelos profissionais e pacientes no atendimento a diabetes. Considera as dificuldades das mudanças requeridas pelos primeiros frente ao necessário empoderamento dos segundos. Isso não significa um incremento do individualismo do paciente, mas uma opção pela lógica do cuidado em contraste com a lógica da escolha, pautada pelos agentes da biomedicina. Outros estudos evidenciam o lugar os profissionais do serviço de saúde no cuidado da diabete (PUCCI et al., 2018), contudo, para que alcancem sucesso em seus objetivos, eles necessitam levar em conta as representaçóes sociais dos pacientes e desenvolver uma abordagem interdisciplinar (COSTA; COUTINHO, 2016).

Ao reconhecerem as limitações do corpo atual, os sujeitos entrevistados apresentaram possibilidades para gerenciar sua nova condição biológica. Tentaram habituar-se ao corpo alterado, distanciando-se das experiências reiteradas e cotidianas do corpo habitual para responsabilizar-se pelas demandas experimentadas no seu corpo atual e aceitando sua nova condição corpórea.

Então eu tinha uma vida normal, agora eu também tenho uma vida normal, só com limitaçôes. Todos aqueles excessos, que nós diabéticos cometemos, nós só vamos realmente nos responsabilizar e conscientizar, depois do acontecido. [...] porque se talvez a diabetes não tivesse me atingido, eu estaria cometendo os excessos até hoje. (Silvio, 68 anos).

Silvio expressa sua concepção sobre o que é viver com o DM. As mudanças, a aquisição de novos hábitos e a adesão ao tratamento são processuais. Por ser uma 
doença crônica, ela exige que as pessoas tenham que conviver com a doença ao longo de sua vida, conforme relata:

Porque uma das coisas que eu aprendi, que não se pode de uma hora para outra. Principal-
mente, o diabetes, essas doenças incuráveis, a gente querer curar na hora. Não vou comer
isso, não vou comer aquilo! Entáo um dos grandes problemas é a pessoa saber o que pode
e o que não pode. (Silvio, 68 anos).

Essa constatação aponta para a diferença entre, por um lado, a adesão ao tratamento, centrada nas prescriçóes terapêuticas médico-centradas e na chamada de atenção aos desvios do prescrito; e por outro, o gerenciamento, focado nas necessidades do usuário com DM, no aspecto processual do aprendizado e na tomada de decisóes, segundo os ritmos do cotidiano da vida. O processo inicia-se com a percepção de sensaçóes desagradáveis e estranhas no corpo alterado pela $\mathrm{DM}$, que vão sendo interpretadas por conhecimentos dos diversos sistemas de representação social da doença, principalmente pelo subsistema profissional que ajuda a distinguir entre glicemia alta ou baixa, pela auscultação dos sinais do corpo, através do teste do dedo, levando a microdecisôes técnicas para contornar essas sensaçôes, baseadas no autorrastreamento e gerenciamento da diabetes (DANESI; PRALONG; PIDOUX, 2018). Desta forma, a tomada de consciência do corpo alterado, através do uso de meios técnicos para examinar seus sinais e reagir diante deles, conduz as pessoas a um processo de integração entre o corpo habitual e o corpo atual, de forma a corresponder e poder administrar a doença como uma possibilidade na direção do gerenciamento e do autocuidado.

Conclui-se que o processo de evolução do DM pode favorecer aprendizagens em relação ao autocuidado, quando se percebe o corpo como o sismógrafo para aprender a monitorar e gerenciar as alteraçóes provocadas pela doença. Elas estão relacionadas às necessidades impostas ao corpo atual, mas vivenciadas como uma negação e não aceitação do mundo vivido, expresso pelo corpo habitual. A persistência das alteraçôes e necessidades do corpo atual obriga a perceber e interpretar seus sinais corporais, representando para si a doença e, com a assistência e os meios técnicos do sistema profissional, aprender a gerenciar essas alteraçôes e necessidades. Esse gerenciamento como autocuidado se estabelece no momento que os sujeitos conseguem diminuir as distâncias entre um corpo habitual saudável e um corpo atual alterado pela DM, encontrando novas formas de vivenciar o mundo e suas limitaçôes num corpo assumido que agora é a mediação para se situar e construir seu mundo de significados. 


\section{Considerações finais}

O acompanhamento longitudinal de pessoa com DM necessita uma atençáo especial ao modo como ela sente seu corpo, porque a percepçáo dos sintomas e dos sinais corporais da doença são o caminho para saber lidar com as alteraçóes e necessidades que a diabete vai revelando no corpo. Assim o corpo torna-se o sismógrafo para o aprendizado do autocuidado.

No início, quando os exames confirmam o diagnóstico da DM, a pessoa vive um momento de estranhamento e cisão entre a experiência do seu corpo habitual saudável e a revelação das alteraçôes do seu corpo atual, com suas repercussóes emocionais. A prescrição de medicamentos, dieta e exercícios físicos para enfrentar o problema são um percurso cheio de dificuldades e um desafio para sua implementação.

Esse caminho vai sendo trilhado com acertos, infidelidades e adaptaçôes para encontrar o gerenciamento adequado do que é prescrito aos ritmos e rotinas da vida cotidiana. Para encontrar esse gerenciamento afinado com a subjetividade da pessoa, são importantes as orientações do subsistema profissional, mas também os conhecimentos do subsistema familiar e popular que oferecem dicas da experiência de outras pessoas. Por outro lado, para construir a via do autocuidado, é crucial estar atento ao tempo e à duraçáo necessária da experiência com a doença para que decante o aprendizado. Essa temporalidade acontece nas sensaçóes do corpo que precisam ser auscultadas em seus sinais para reencontrar o corpo habitual a partir do gerenciamento das alterações do corpo atual, pois ele é a base para situar-se no mundo, construir significados e lidar com a vida.

Essas considerações sobre a percepção e a auscultação do corpo como sismógrafo das manifestaçôes da diabetes e como indicativo das medidas a serem tomadas para lidar com seus sintomas são centrais para o gerenciamento e o autocuidado da pessoa com diabetes e para o atendimento dos profissionais da saúde, especialmente as enfermeiras, que acompanham mais de perto e longitudinalmente essas pessoas no cotidiano da vida. ${ }^{1}$

\section{Referências}

AMORIM, M. M. A.; RAMOS, N.; GAZZINELI, M. F. Alimentação na visão das pessoas com diabete mellitus: contributo das representaçôes sociais. Psychology, Community \& Health, v. 7, n. 1, p. 97-108, 2018. 
ATAÍDE, M. B. C.; DAMASCENO, M. M. C.; MOREIRA, R. V. O. O mundo dicotomizado do diabético jovem: reflexão filosófica à luz do pensamento de Merleau-Ponty. Revista Educação em Debate. Fortaleza, v. 14, p. 1-7, 2001.

BARDIN, L. Análise de conteúdo. 1. ed. Lisboa: Edições 70, 2011.

CANESQUI, A. M. Consideraçôes sobre a experiência do adoecimento e do sofrimento. Ciência \&. Saúde Coletiva, v. 23, n. 8, p. 2466 (Editorial), 2018.

COSTA, F. G.; COUTINHO, M. P. L. Representaçóes sociais no contexto da diabetes mellitus. Psicologia em Estudo. Maringá, v. 21, n. 1, p. 175-185, 2016.

DANESI, G.; PRALONG, M.; PIDOUX, V. Embodiment and agency through self-tracking practices of people living with diabetes. In: AJANA, B. (Ed.). Metric sulture. Bingley (UK): Emerald Publishing Limited, 2018. p. 117-135.

ISER, B. P. M. et al. Prevalência de diabetes autorreferido no Brasil: resultados da Pesquisa Nacional de Saúde 2013. Epidemiologia e Serviços de Saúde. Brasília, v. 24, n. 2, p. 305-314, 2015.

HIGUERAS, M. C. H. Significados del cuerpo en personas con diabetes mellitus en la ciudad de Cali. Revista de Investigación: Cuerpo, Cultura y Movimiento. Colombia, v. 6, n. 1, p. 31-43, 2016.

JOWSEY, T. Time and chronic illness: a narrative review. Quality of Life Research, v. 25, n. 5 , p. 1093-1102, 2016.

KNECK, A.; KLANG, B.; FAGERBERG, I. Learning to live with diabetes - integrating an illness or objectifying a disease. Journal of Advanced Nursing, v. 68, n. 11, p. 2486-2495, 2012.

KNECK, A. et al. Encumbered by vulnerability and temporality - the meanings of trigger situations when learning to live with diabetes. Journal of Clinical Nursing, v. 25, p. 28742883, 2016.

LEE, A. A. et al. Diabetes self-management and glycemic control: The role of autonomy support from informal health supporters. Health Psychology, v. 38, n. 2, 122-132, 2019.

LOPES, A. A. F. Cuidado e empoderamento: a construção do sujeito responsável por sua saúde na experiência do diabetes. Saúde e Sociedade, v. 24, n. 2, p. 486-500, 2015.

LUCHERINI, M. Performing diabetes: felt surveillance and discreet self-management. Surveillance \& Society, v. 14, n. 2, p. 259-276, 2016.

LUCHERINI, M. Representing diabetes: 'rightside' and 'chaos' in autobiography. Emotion, Space and Society v. 31, p. 10-17, 2019.

MERlEAU-PONTY, M, Fenomenologia da percepção. Trad. de Carlos Alberto Ribeiro de Moura. 2. Ed. São Paulo: Martins Fontes, 1999.

MENDES, E. V. O cuidado das condiçôes crônicas na Atenção Primária à Saúde: o imperativo da consolidação da Estratégia Saúde da Família. Brasília: OPAS, 2012. 
MORÉ, C. L. O. A entrevista em profundidade ou semiestruturada, no contexto da saúde: dilemas e desafios de sua construção e aplicação. In: ATAS. Investigação Qualitativa nas Ciências Sociais do $4^{\circ}$ Congresso Ibero-Americano em Investigação Qualitativa e $6^{\circ}$ Simpósio Internacional de Educação e Comunicação. Lisboa (Portugal): Ludomedia, 2015, p. 126-131.

NASCIMENTO, L. C. N. et al. Saturação teórica em pesquisa qualitativa: relato de experiência na entrevista com escolares. Revista Brasileira de Enfermagem, v. 71, n. 1, p. 243-8, 2018.

PUCCI, V. R. et al. O autocuidado em indivíduos com diabetes mellitus na atenção primária à saúde: compreensão sobre o papel da alimentação. Revista da Atenção Primária à Saúde. Juiz de Fora, v. 21, n. 3, p. 418-427, 2018.

SANTOS, M. A. et al. Corpo, saúde e sociedade de consumo: a construção social do corpo saudável. Saúde e Sociedade, v. 28, n. 3, p. 239-252, 2019.

SILVA, D. G. V. et al. Pessoas com Diabetes Mellitus: suas escolhas de cuidado e tratamentos. Revista Brasileira de Enfermagem. Brasília, v. 59, n. 3, p. 297-302, 2006.

SILVA, S. E. D. et al. Meu corpo dependente: representações sociais de pacientes diabéticos. Revista Brasileira de Enfermagem. Brasília. v. 63, n. 3, p. 404-409, 2010.

SOUZA, V. P. et al. Conhecimento e práticas de usuários com diabetes mellitus sobre a automonitorização da glicemia capilar no domicílio. Revista Fundamental Care Online. Rio de Janeiro, v. 10, n. 3, p. 737-745, 2018.

TOUSO, M. F. S. et al. Dificuldades emocionais e psicológicas em indivíduos com diabete mellitus. Revista de Enfermagem UFPE Online. Recife, v. 10, n. 2, p. 524-530, 2016.

\section{Nota}

${ }^{1}$ J.R. Junges contribuiu na concepção, análise e interpretação dos dados, revisão crítica do conteúdo e aprovaçáo da versáo final do artigo. W. V. de Camargo escreveu o projeto de pesquisa, coletou e transcreveu as entrevistas, fez as primeiras análises e discussões e redigiu as versões iniciais do artigo. 


\section{Abstract}

Body perception and self-care in subjects with diabetes mellitus 2: a phenomenological approach

This is a qualitative research that aimed to analyze the perception of the body and self-care in subjects affected by diabetes mellitus 2 . Ten participants were interviewed, assisted by a Family Health Strategy located in the metropolitan region of Porto Alegre-RS, Brazil. As a methodological resource, semi-structured interviews were used; the data were analyzed through thematic content analysis proposed by Bardin. As a theoretical matrix, the phenomenological perspective of Merleau-Ponty was used. The analysis of the narratives made it possible to create two categories: 1) body wit: facing the unexpected; 2) assumed body: learning to live with the disease. The interpretation of the data revealed that the subjects showed attitudes of surprise, feeling sad, not accepting the changes in the body, but also conforming to the diagnosis. The subjects went through dietary difficulties and medication management until they assumed the body altered by the incorporation of new habits. In conclusion, it is noteworthy that only with the alignment of the habitual body to the current body, by incorporating treatment procedures, does the attitude of self-care begin to be part of everyday life.

> Keywords: Public Health; chronic disease; diabetes mellitus; body; self-care. 